\title{
A ATUAÇÃO DAS UNIVERSIDADES NAS TRANSFORMAÇÕES URBANAS. O CASO DA UNIVERSIDADE DO OESTE PAULISTA, UNOESTE
}

\author{
Rafaella Rúbia do Prado Barbosa, Korina Aparecida Teixeira Ferreira da Costa
}

Universidade do Oeste Paulista - UNOESTE, curso de Arquitetura e Urbanismo, Presidente Prudente, SP. E-mail: rafaella1995@hotmail.com

\section{RESUMO}

O presente artigo apresenta um breve levantamento histórico do ensino superior no Brasil e também um estudo sobre o surgimento da Universidade do Oeste Paulista (UNOESTE), evidenciando as consequências deste acontecimento na cidade de Presidente Prudente e região. Como metodologia foi adotado levantamentos bibliográficos, através de documentos fornecidos pela própria Universidade. Sendo assim, através destas análises sobre a temática referida e tomando como estudo de caso a Unoeste, o objetivo principal deste trabalho foi compreender as transformações que o surgimento de uma instituição de ensino superior gera na cidade em que é implantada e também nas escalas regional, estadual e até mesmo nacional, já que existem alunos oriundos de locais bastante distantes.

Palavras-chave: Ensino superior; Universidades; UNOESTE; Transformações; Presidente Prudente.

\section{THE ACTING OF THE UNIVERSITIES IN THE URBANE TRANSFORMATIONS. THE CASE OF THE UNIVERSITY OF THE WEST PAULISTA, UNOESTE}

\begin{abstract}
The present article presents a short historical lifting of the superior teaching in Brazil and also a study on the appearance of the University of the West Paulista (UNOESTE), showing the consequences of this event up in the city of President Prudente and region. Since methodology was adopted bibliographical liftings, through documents supplied by the University itself. Being so, through these analyses on the above-mentioned theme and taking like case study the Unoeste, the main objective of this work went to understand the transformations that the appearance of an institution of superior teaching produces in the city in which it is introduced and also in the regional, state scales and even national, since there are pupils originating from quite distant places.
\end{abstract}

Keywords: Superior teaching; Universities; UNOESTE; Transformations; Presidente Prudente.

\section{INTRODUÇÃO}

O presente estudo iniciou-se por um resgate histórico da instituição de ensino superior, o que de acordo com Bohrer et al. (2008), Simões (2013) e Humerez e Jankevicius (2015), ocorreu a partir do final da Idade Média, mais especificadamente no final do século XI, no continente europeu estendendo-se por este rapidamente e tempos depois pelo mundo inteiro.

Humerez e Jankevicius $(2015$, p. 1) completam ponderando que "[A]s Universidades medievais europeias lançaram as bases da Educação Superior moderna, definindo os conceitos de bacharelado, licenciatura, mestrado, doutorado, utilizados até hoje"

Segundo Bohrer et al (2008) e Humerez e Jankevicius (2015) apenas no início do século XVI, que as universidades começaram a despontar pela América Latina, mediante uma influência europeia. Contudo, mesmo com tal acontecimento, "[Q]uase todos os países latino-americanos já Colloquium Socialis, Presidente Prudente, v. 01, n. Especial 2, Jul/Dez, 2017, p.618-623. DOI: 10.5747/cs.2017.v01.nesp2.s0202 
possuíam uma ou mais universidades, com exceção do Brasil" (ROSSATO, 2005 apud BOHRER ET AL, 2008, p. 5).

A importância deste trabalho baseia-se no fato de que o aparecimento de uma Universidade traz novos rumos para a cidade em que é instalada, alcançando proporções regionais, estaduais e até mesmo nacionais.

Posto isto, o presente trabalho propõem-se a entender a importância do surgimento do ensino superior no Brasil, ainda que tardiamente em relação aos demais países, e, tomando como objeto de estudo a Universidade do Oeste Paulista (UNOESTE) localizada na cidade de Presidente Prudente- SP, compreender as transformações que o aparecimento desta acarretou na cidade de Presidente Prudente e região.

\section{METODOLOGIA}

A metodologia empregada neste trabalho enquadra-se no perfil qualitativo e é fundamentada em leituras sobre a história do ensino superior no Brasil com uma breve explanada no âmbito mundial e também sobre o surgimento da Universidade do Oeste Paulista e seu desenvolvimento até os dias atuais.

Inicialmente foram feitos levantamentos bibliográficos acerta da temática referida para melhor compreensão desta, para posteriormente desenvolver análises com base nas leituras realizadas e através dos documentos fornecidos pela própria Unoeste.

\section{BREVE HISTÓRICO DO ENSINO SUPERIOR NO BRASIL}

Entre 1549 a 1759, a educação no Brasil foi orientada pela companhia de Jesus, onde padres Jesuítas catequizavam indígenas, escravos, colonos e senhores de engenho com o intuito de perpetuarem o catolicismo e as práticas europeias, originando alguns colégios e seminários (BOHRER ET AL, 2008; HUMEREZ E JANKEVICIUS, 2015).

Ainda conforme Bohrer et al (2008) e Humerez e Jankevicius (2015), a partir de 1759 os Jesuítas foram mandados embora do país devido às reformas promovidas por Marquês Pombal, que instalou escolas favoráveis às intenções do Estado contrariando os colégios Jesuítas.

Conforme Humerez e Jankevicius (2015), nos anos que se seguiram, grande parte dos habitantes do Brasil não possuíam educação superior, os que tinham ou eram estrangeiros ou aqueles que iam estudar em outros países, especialmente em Portugal, na Universidade de Coimbra tida como a primeira universidade do Brasil, já que graduou mais de 2.500 brasileiros, somente em 1808 esta realidade começou a mudar quando a Família Real mudou-se para o Brasil e surgiram as primeiras Faculdades.

Segundo Simões (2013) já no Brasil república, a partir de 1931, Francisco Campos, atual ministro da Educação e Saúde Pública na época, através de alguns decretos ligados ao ensino superior, estabelece uma fortalecimento da educação superior que ganhou novos rumos.

Porém foi só em 1969, que ocorreu a reforma Universitária, que tinha como um de seus objetivos "[...] transformar a universidade estatal em universidade privada, ou seja, colocar o ensino superior em bases lucrativas e estruturar a universidade em moldes empresariais" (GUTIERREZ, 2013, p.22). Em decorrência disto houve um aumento considerável nas matrículas das instituições privadas durante a reforma, que também aspirava por afastar grupos de estudantes que formavam órgãos e grêmios e de certa forma interferiam na administração da universidade (GUTIERREZ, 2013).

Uma outra reforma preconizou a de 1969, que foi a Reforma da FAU USP (Faculdade de Arquitetura e Urbanismo da Universidade de São Paulo) de 1962, ambas tinham em comum o propósito de que o ensino tradicional se extinguisse, porém tinham diferenças entre si, dentre elas podemos destacar que a Reforma da FAU originou-se no meio da mesma durante o período Colloquium Socialis, Presidente Prudente, v. 01, n. Especial 2, Jul/Dez, 2017, p.618-623. DOI: 10.5747/cs.2017.v01.nesp2.s0202 
democrático e foi inserida no ensino de forma empírica enquanto a reforma de 1969 foi elaborada por um grupo que a instalava de forma obrigatória na Universidade, especialmente nas públicas, devido ao pensamento autoritário contido nesta, este tem suas origens em 1964 com o Golpe Militar (PEREIRA, 2009).

Sendo assim, pode-se entender, com base em Pereira (2009), que a Reforma de 1969 se estabeleceu durante a ditadura militar e foi sustentada pelo autoritarismo vigente na época, todavia vale lembrar que o ensino superior no Brasil, já vinha sendo interferido por este regime, mesmo antes da reforma.

Contudo, o século XX foi marcado por um notável desenvolvimento em vários setores da sociedade, inclusive o do ensino superior, que sobretudo na segunda metade do século experimentou um enorme avanço (ROSSATO, 2005 apud BOHRER ET AL, 2008). Simões (2013) completa evidenciando que a partir do final do século XX destaca-se o crescimento do ensino superior, com o surgimento de inúmeras universidades, faculdades e ingressantes.

Desta forma, constata-se que a educação brasileira possuiu três fases até o presente momento, que são destacadas por Piletti (apud BOHRER ET AL, 2008, p.06):

No período colonial, o ensino das principais letras tinha a função de criar condições necessárias à catequese e à imposição dos costumes europeus; no período monárquico foi estabelecido, legalmente, o ensino primário, o curso secundário regular e a escola superior; e no período republicano as leis de educação foram modificadas ao invés de modificar a realidade.

Com base em tais fatos, pode-se concluir que o ensino superior no Brasil não se destaca em meio aos outros países, como os europeus, por possuir uma defasagem de centenas de anos em relação a sua instauração. Contudo o surgimento de uma Universidade traz transformações para a cidade onde é instalada, gerando mais desenvolvimento e crescimento, como observou-se no caso da Unoeste.

\section{ESTUDO DE CASO: A UNIVERSIDADE DO OESTE PAULISTA (UNOESTE)}

De acordo com Santos (1999), no dia 14 de setembro de 1917 surgia a cidade de Presidente Prudente, idealizada e colonizada por duas importantes figuras da história prudentina, o coronel Francisco de Paula Goulart e o coronel José Soares Marcondes.

A cidade despontou-se a partir da linha férrea e da estação ferroviária e segundo Resende (1992, p.28), primordialmente formou-se "[U]m quadrilátero formado pelas atuais avenidas: Brasil, Manoel Goulart, Cel. Marcondes e Washington Luís".

A cidade cresceu e anos depois surgia a Universidade do Oeste Paulista, que trouxe uma nova vitalidade para Presidente Prudente, possibilitando que pessoas oriundas de várias partes do país se instalassem na cidade, neste momento, vários setores da economia se desenvolveram, tais como: "setores hoteleiros, casas de pasto, lojas comerciais, instituições de crédito e organizações imobiliárias" (UNOESTE, 1982, p. 69).

Hoje a instituição conta com três Campus, cujo primeiro prédio da Universidade foi inserido na rua José Bongiovani, que era um local pouco movimentado, porém, atualmente é uma rua com fluxo intenso e ativa tanto para veículos quanto para pedestres.

Tudo isto só foi possível em razão da coragem e ousadia do grande visionário e empreendedor chamado Agripino de Oliveira Lima Filho, que considerou a possibilidade e necessidade de instalação de uma universidade no Oeste Paulista, julgando a importância do ensino superior no Brasil. Assim, em 1972 nascia a APEC (Associação prudentina de educação e cultura) fundada para ministrar o ensino superior e ser a entidade mantedora da futura Universidade do Oeste Paulista (UNOESTE, 1977). 
Segundo a Unoeste (1977, p. 5-6), "[E]m 3 de outubro de 1972, o Excelentíssimo Senhor Presidente da República General Emílio Garrastazu Médici assinava o decreto no 71.190, criando a faculdade de ciências, letras e educação de Presidente Prudente, primeira Faculdade criada pela nova entidade mantedora".

Neste mesmo ano deu-se início à construção da edificação onde se instalaria a Faculdade, que ficaria localizada no bairro José Bongiovani, todavia, enquanto o prédio não era finalizado, dependências do Centro do Professorado Paulista eram cedidas para reuniões e assembleias e posteriormente, no Colégio Cristo Rei iniciava-se os primeiros cursos da Universidade, e já no ano seguinte em 1973 as aulas foram transferidas para o bloco A do campus I (UNOESTE, 1977).

De acordo com a Unoeste (1977) o progresso da APEC e a carência de cursos superiores na região fez com que surgissem outras faculdades. Já em 1977, cinco anos após sua fundação, a Universidade possuía uma série de faculdades e cursos, dentre eles: a Faculdade de Ciências, Letras e Educação, com os cursos de Letras, Pedagogia, Estudos Sociais, Educação Artística, Ciências com habilitação em Química, Física Matemática e Biologia; Faculdade de Odontologia; Faculdade de Formação de Professores de Disciplinas Especializadas; Faculdade de Farmácia e Bioquímica; Escola de 1으 e 20 Graus; e o Centro de Aperfeiçoamento e Especialização.

Devido a este progresso, se fez necessário a construção de outros prédios junto ao prédio inicial, "prédios modernos, grandiosos, que dão uma nota alegre na paisagem urbanística da cidade" (UNOESTE, 1977, p.8).

Figura 1 - Evolução do conjunto arquitetônico da APEC, Campus I

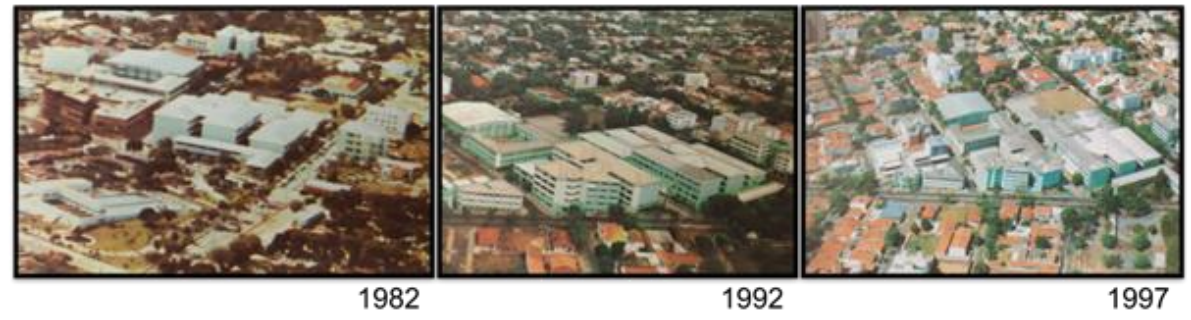

(Fonte: Unoeste, 1982; 1992; 1997. Modificado pelas autoras, 2017.)

Na figura 1 nota-se o desenvolvimento da Universidade, que ao logo dos anos foi expandindo suas construções e concomitantemente alterando seu entorno, este sofreu um progresso tanto economicamente quanto socialmente que se reflete até os dias atuais.

Segundo Unoeste (1982, p. 10-11) tempo depois, "[0] idealizador da APEC prepara o futuro, para tal, adquirindo uma área de terras à beira da Rodovia Raposo Tavares [...]", denominada hoje como o Campus II da Universidade do Oeste Paulista que totaliza uma área total de 37 alqueires paulista (UNOESTE, 1982).

Em 1982 tal área já possuía um salão de festa concluído, atualmente conhecido como o salão Limoeiro, e aguardava a aprovação para novos cursos que se instalariam em prédios construídos no novo Campus, tais como: Agronomia, Veterinária, Zootecnia e ramos da Engenharia: Agrícola, Florestal, da Pesca, Química e outras especialidades (UNOESTE, 1982).

Já em 1987 o Campus II é inaugurado, no mesmo ano, no dia 12 de fevereiro a Unoeste é reconhecida pela Portaria no 83/MEC e em 3 de agosto se inicia as atividades acadêmicas no campus (UNOESTE, 2002; 2012).

Conforme a Unoeste (1987), no ano de 1992, estavam em construção um prédio de 5.132 $\mathrm{m}^{2}$, com 44 novas salas de aula, canil e uma capela para cerimônias religiosas. Em 1997 novas construções surgem como: "[...] o salão 'Torre de Cristal', Igreja, fonte luminosa, centros de convivência com lanchonetes e quiosques, áreas com churrasqueiras e centenas de mesas para confraternização ao ar livre [...]" (UNOESTE, 1992). 
Devido a sua implantação tão distante do centro da cidade, o Campus II promoveu a expansão urbana nas suas proximidades, como observa-se na figura 2, região pela qual a cidade não se expandia e possuía difícil acesso. Vale ressaltar que o surgimento da Universidade como um todo proporcionou o desenvolvimento de Presidente Prudente, que em virtude do crescimento dessa instituição atraia diversos investimentos e pessoas.

Figura 2 - Expansão do município de Presidente Prudente nas proximidades do Campus II da Unoeste

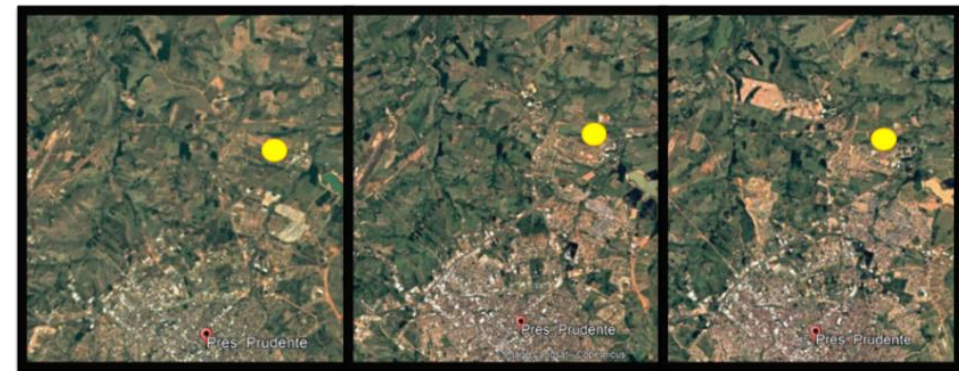

LEGENDA:

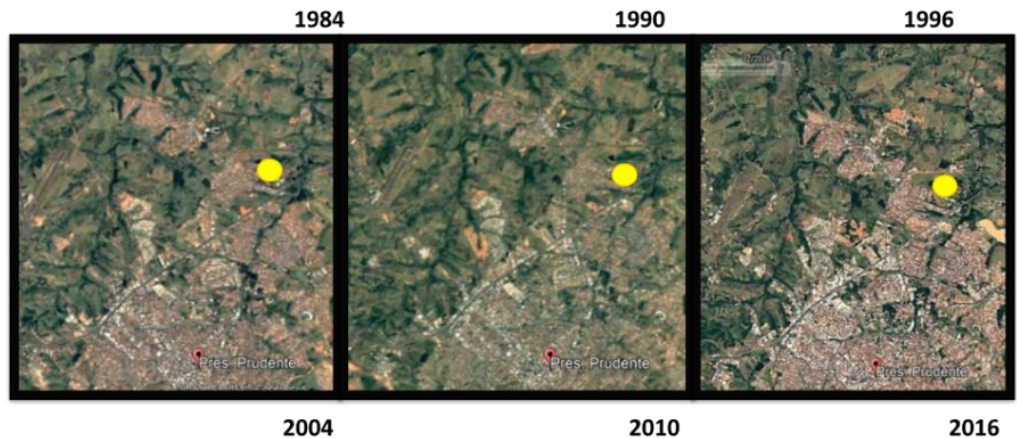

Campus I

(Fonte: Google Earth 1984; 1990; 1996; 2004; 2010; 2016. Modificado pelas autoras, 2017.)

Ano após ano a Universidade se consolidava e em 2002 já possuía três campus: o Campus I, Campus II e Campus III, este último estava em um estágio crescente de estruturação e receberia toda a parte de exploração agropecuária e o plantio de inúmeras mudas de árvores frutíferas e ornamentais (UNOESTE, 1997).

Atualmente, a universidade possui 57 cursos presenciais e 8 a distância, além de oferecer pós graduação, mestrado, cursos técnicos e um significativo atendimento a comunidade, gerando um desenvolvimento progressivo para a cidade e região e seu reconhecimento como uma das maiores universidades do estado.

\section{CONCLUSÃO}

Com base neste trabalho pode-se verificar que o ensino superior no Brasil ainda é recente se comparado aos países europeus, porém vem se desenvolvendo e se impondo mundialmente.

Por fim, conclui- se que o aparecimento de uma Universidade em determinada cidade gera transformações urbanas não somente nesta como também na região, conforme observamos no caso da Unoeste. Vale lembrar que este estudo é parcela integrante do TCC, do curso de Arquitetura e Urbanismo da Unoeste, ainda em andamento.

\section{REFERÊNCIAS BIBLIOGRÁFICAS}

BOHRER, I. N. et al. A história das universidades o despertar do conhecimento. In: JORNADA NACIONAL DA EDUCAÇÃO, 14, 2008, Santa Maria. Anais eletrônicos... Santa Maria: UNIFRA, 2008. Disponível em: <http://www.unifra.br/eventos/jne2008/Trabalhos/114.pdf>. Acesso em: 17 abr. 2008.

Colloquium Socialis, Presidente Prudente, v. 01, n. Especial 2, Jul/Dez, 2017, p.618-623. DOI: 10.5747/cs.2017.v01.nesp2.s0202 
GUTIERREZ, E. J. B (org.). A Associação Brasileira de Ensino de Arquitetura e os seus primeiros tempos (1973-1985). In: MONTEIRO, Ana Maria et al. A Construção de um Novo Olhar sobre o Ensino de Arquitetura e Urbanismo no Brasil: 40 anos da ABEA. Brasília: ABEA, 2013. p. 18- 28

HUMEREZ, D. C; JANKEVICIUS, J. V. EVOLUÇÃO HISTÓRICA DO ENSINO SUPERIOR NO BRASIL. Disponível em: < http://biblioteca.cofen.gov.br/wp-content/uploads/2015/05/Evolucao-Historicano-ensino-superior-no-brasil.pdf>. Acesso em: 18 abr. 2017.

PEREIRA, J. A. Desenho Industrial e Arquitetura no Ensino da FAU USP (1948-1968). 2009. $438 \mathrm{f}$. Tese (Doutorado em Teoria e História da Arquitetura e do Urbanismo) - Escola de Engenharia de São Carlos, Universidade de São Paulo, São Carlos -SP

RESENDE, B. Raízes Prudentinas. São Paulo: Senac, 1992.

SANTOS, W. Pioneiros e memória de Presidente Prudente. Presidente Prudente: [s.n.] ,1999.

SIMÕES, M. L. O surgimento das universidades no mundo e sua importância para o contexto da formação docente. Revista Temas em Educação, João Pessoa, v.22, n.2, p. 136-152, jul.-dez. 2013. Disponível em: <http://periodicos.ufpb.br/index.php/rteo/article/view/17783/10148>. Acesso em: 18 abr. 2017.

UNIVERSIDADE DO OESTE PAULISTA. Presidente Prudente, 1982-. Quinquenal.

UNIVERSIDADE DO OESTE PAULISTA. Presidente Prudente, 1987-. Quinquenal.

UNIVERSIDADE DO OESTE PAULISTA. Presidente Prudente, 1992-. Quinquenal.

UNIVERSIDADE DO OESTE PAULISTA. Presidente Prudente, 1997-. Quinquenal.

UNIVERSIDADE DO OESTE PAULISTA. Presidente Prudente, 2002-. Quinquenal.

UNIVERSIDADE DO OESTE PAULISTA. Presidente Prudente, 2012-. Quinquenal. 